\title{
Sustentabilidade Ecológica do Espeleoturismo na Serra da Bodoquena, Mato Grosso do Sul
}

\section{Ecological Sustainability of Speleotourism in the Serra da Bodoquena, Mato Grosso do Sul}

Heros Augusto Santos Lobo ${ }^{1}$

Edvaldo Cesar Moretti ${ }^{2}$

\begin{abstract}
Resumo
O presente artigo apresenta uma análise da estrutura e produção do espeleoturismo na Serra da Bodoquena, sob o enfoque do ideário de ecoturismo e da sustentabilidade ecológica. A metodologia de pesquisa incluiu levantamentos documentais e de campo em cavidades naturais turísticas. As discussões apresentam aspectos técnico-metodológios como caminhos viáveis para um espeleoturismo com princípios ecológicos e conservacionistas. Conclui-se que o espeleoturismo pode se firmar não somente como um segmento, mas também como uma nova forma de se fazer o turismo na Serra da Bodoquena. Para tanto, deve identificar novas possibilidades de procedimentos de gestão e manejo ambiental que possam ir além dos paradigmas e modelos vigentes.
\end{abstract}

Palavras-chave: ecoturismo; espeleoturismo; gestão ambiental; Bonito-MS.

\begin{abstract}
This article presents the results of an analysis of the structure and production of speleotourism in the Serra da Bodoquena, based on the precepts of ecotourism and ecological sustainability. The methodology included a survey of documents and fieldwork in natural cavities exploited for tourism. The discussion presents a technical-methodological approach for a speleotourism based on ecology and conservation. The study concludes that speleotourism can be established, not only as a specific market segment, but also as a new kind of tourism in the Serra da Bodoquena. For this, have to identify new opportunities for environmental management and control of impacts that may go beyond the existing paradigms and models.
\end{abstract}

Keywords: ecotourism; speleotourism; environmental management; Bonito-MS.

\footnotetext{
${ }^{1}$ Bacharel em Turismo (Universidade Anhembi Morumbi - UAM). Especialista em Gestão e Manejo Ambiental em Sistemas Florestais (Universidade Federal de Lavras - UFLA). Mestre em Geografia (Universidade Federal de Mato Grosso do Sul - UFMS). Doutorando em Geociências e Meio Ambiente (Universidade Estadual Paulista - UNESP/Rio Claro). Consultor autônomo, Editor-chefe dos periódicos cietíficos Pesquisas em Turismo e Paisagens Cársticas e Espeleo-Tema. E-mail: heroslobo@hotmail.com

${ }^{2}$ Graduado, especialista, mestre e doutor em Geografia (Universidade Estadual Paulista - UNESP/Rio Claro). Pós-doutor em Geografia (Universidade Estadual de Campinas - UNICAMP). Professor Adjunto da Universidade Federal da Grande Dourados - UFGD/MS. Líder do Grupo de Pesquisas Território e Ambiente GTA. E-mail: emoretti@ufgd.edu.br
} 


\section{Introdução}

O turismo está entre as principais atividades econômicas desenvolvidas na Serra da Bodoquena, região consagrada no cenário turístico nacional e internacional e que tem no município de Bonito seu principal vetor de desenvolvimento turístico. Tem como principais atrativos naturais os rios de águas límpidas, as cachoeiras que mudam de tamanho e forma em função da dinâmica do ambiente cárstico, as trilhas por entre remanescentes florestais e as cavernas - alvo do presente estudo. Estas foram escolhidas tendo em vista a sua atratividade para o turismo, bem como sua fragilidade latente, o que requer cuidados específicos de conservação.

O turismo em cavernas - ou espeleoturismo - ainda é um campo recente de estudos dentro do espectro de possibilidades de planejamento, manejo e gestão do turismo em áreas naturais. $\mathrm{Na}$ Serra da Bodoquena, poucos são os estudos anteriores que versam de forma específica sobre este tema. Dentre eles, destacam-se os trabalhos de: Lino et al. (1984), com uma descrição geral das cavidades naturais turísticas da região; Labegalini (1996), com uma proposta de mínimo impacto para estruturação turística da Gruta do Lago Azul; Boggiani et al. (2007), com o estudo de impactos ambientais da Unidade de Conservação Monumento Natural gruta do Lago Azul, incluindo a caverna de mesmo nome e também a gruta Nossa Senhora Aparecida; e o estudo feito por Silva e Camargo (2008), enfocando a valoração econômica das cavernas da região do rio Salobra, Norte da Serra da Bodoquena.

De forma geral, pode-se dizer que os estudos citados apontam soluções considerando as pontualidades de cada caverna enfocada. Nenhum deles buscou realizar uma análise detalhada do ideário e da representatividade do espeleoturismo de forma mais ampla na Serra da Bodoquena, ao que a pesquisa de mestrado que deu origem a este artigo buscou apresentar a sua contribuição ao tema ${ }^{3}$. Para tanto, os estudos realizados buscaram responder a seguinte questão: como os procedimentos técnicos de manejo e as características das cavernas podem contribuir para a sustentabilidade ecológica do espeleoturismo? De forma mais específica, a pesquisa teve por objetivo analisar o uso do patrimônio espeleológico e a estrutura da atividade espeleoturística na Serra da Bodoquena, sob o enfoque do ideário de ecoturismo e de sustentabilidade ecológica.

\footnotetext{
${ }^{3}$ Os autores agradecem aos professores Dr. Álvaro Banducci Júnior (UFMS), Dra. Icléia de Albuquerque Vargas (UFMS) e Dra. Mirian Rejowski (USP/UCS) por suas contribuições e sugestões em diferentes fases da pesquisa de mestrado que deu origem a este artigo; e à profa. Dra. Linda Gentry El-Dash (Unicamp) pela versão em inglês do resumo.
} 


\section{Métodos e Etapas da Pesquisa}

Na primeira fase dos levantamentos foi executada ampla análise documental sobre a evolução do turismo, do ecoturismo e do espeleoturismo, bem como sobre o histórico da evolução do turismo na Serra da Bodoquena. Na segunda foi realizado o trabalho de campo em todas as cavernas da região que possuem relação direta com o turismo. Assim, foram consideradas em um primeiro momento as seguintes cavidades: gruta do Lago Azul, gruta de São Miguel, gruta do Mimoso, gruta Ceita Corê e abismo Anhumas, em Bonito; buraco das Araras e lagoa Misteriosa, em Jardim; e gruta do Urubu-Rei, em Bodoquena. Destas, o estudo focou apenas àquelas onde o turismo ainda se desenvolve (figura 1), já que muitas tiveram a atividade encerrada por questões de ordem legal.

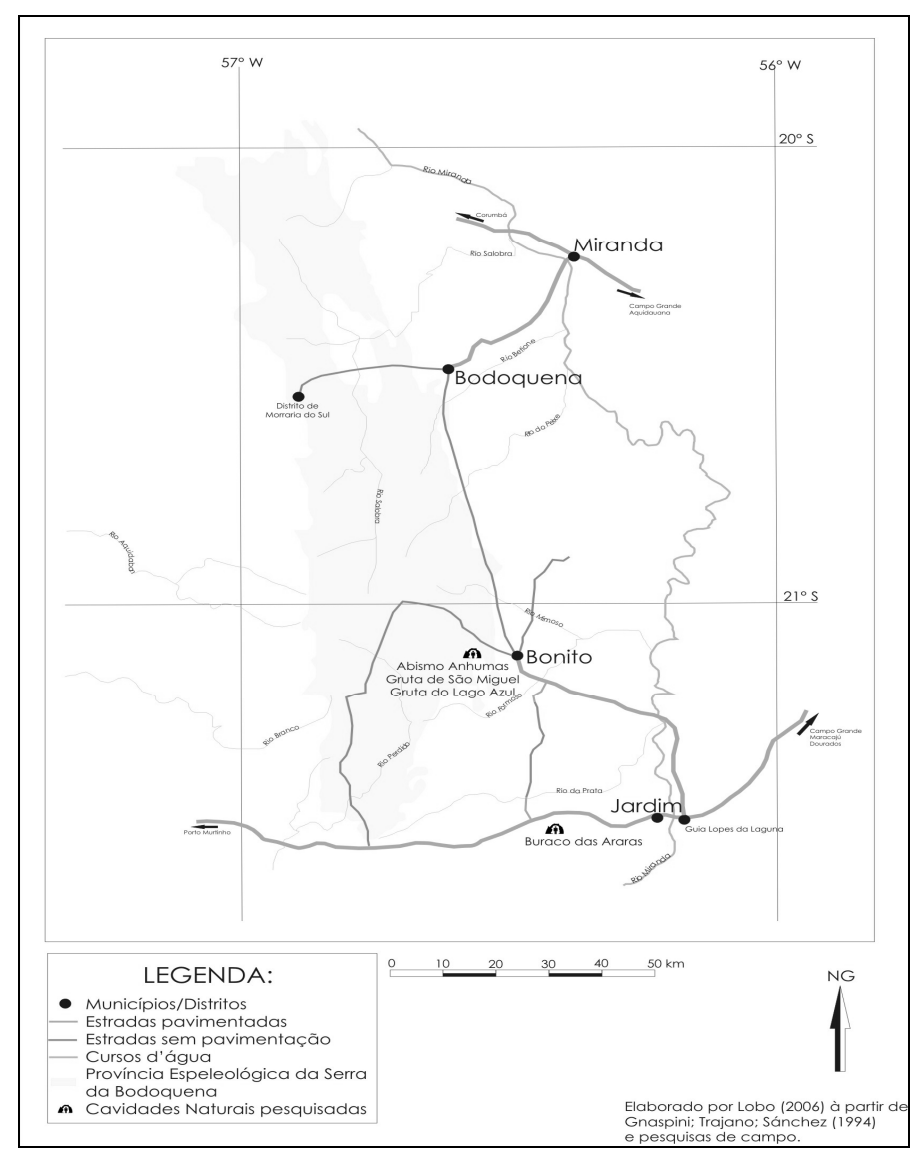

Figura 1 - Mapa com a localização das cavidades naturais estudadas (Adaptado de Lobo, 2006)

Os dados e informações coletados foram analisados sob o ponto de vista técnicometodológico e teórico-conceitual, com base nos trabalhos sobre capacidade de suporte e 
conservação da natureza de Cifuentes-Arias et al. (1999), Swarbrooke (2000) e Boggiani et al. (2007). Tal análise resultou na formulação de propostas que interferem em aspectos técnicos e conceituais da dimensão ecológica do espeleoturismo na região, com implicações decorrentes nas dimensões econômica e social.

\section{Turismo e Espeleoturismo na Serra da Bodoquena}

O município de Bonito tinha sua economia pautada na agropecuária, até que o turismo, gradativamente, vem substituindo esta atividade na importância para o desenvolvimento socioeconômico da região.

Até os anos setenta, os atuais atrativos turísticos eram utilizados como espaços de lazer dos moradores locais, sendo pouco conhecidos por pessoas de outras localidades (BARBOSA e ZAMBONI, 2000; VARGAS, 2001). Em 1988 a Prefeitura Municipal de Bonito desapropriou a área do atual Balneário Municipal, no intuito de fornecer possibilidades de lazer aos munícipes (BOGGIANI, 2001). Foi também à mesma época que a prefeitura editou o primeiro folheto turístico do município (MARIANI, 2003).

Mas os aspectos que levaram ao crescimento definitivo do turismo em Bonito, na opinião de Boggiani (2001), foram: a realização do primeiro curso de guias de turismo de Bonito, entre 1992 e 1993, e a expedição Franco-Brasileira Bonito 92. Essa última foi responsável pela exploração subaquática da gruta do Lago Azul, o que gerou descobertas paleontológicas e imagens na mídia televisiva. Ao mesmo tempo, cresceram as preocupações com os limites de visitação dos atrativos naturais, visando diminuir a sua degradação e, paralelamente, aumentar a segurança dos turistas.

O destino Serra da Bodoquena é vendido como ecoturístico e sustentável. Todavia, ele não deveria ser assim chamado, se observadas as teorias sobre tais formas de turismo, tendo como bases principais: a definição de ecoturismo dada pelo Instituto Brasileiro de Turismo EMBRATUR (BRASIL, 1994); e as duas vertentes - conservacionista ou sustentável - que, conforme análise de Pires (2002), este segmento turístico pode adquirir. Também não seria correto classificar todas as formas de ecoturismo como ecologicamente sustentáveis, pois como aponta Swarbrooke (2002): a motivação dos ecoturistas não é conservar a natureza, mas sim vê-la conservada; o ecoturismo muitas vezes é desenvolvido em áreas de natureza singular, frágil e sob ameaça; e a freqüente procura de novas áreas e produtos ecoturísticos, o que amplia a sua abrangência territorial e sua conseqüente descaracterização ambiental. 
Ao analisar a relação entre o custo ambiental versus o benefício social gerado pelo turismo na região, pode-se obter um resultado relativamente positivo. O turismo, causador de impactos ambientais como qualquer outra atividade antrópica, não apresenta os mesmos níveis de desmatamento e transformação primária da paisagem que outros setores da produção econômica, dado que necessita da natureza conservada para sua existência.

Entretanto, o turismo em Bonito e região ainda se encontra num patamar distante de um ideal de sustentabilidade. De um modo geral conta-se com o bom senso dos proprietários de atrativos na questão dos limites de visitação, de forma a não exceder a sua capacidade de suporte. As pesquisas de campo possibilitaram a observação da pressão exercida pelo poder público local, pelos guias de turismo e alguns outros atores do trade para a ampliação da capacidade de visitação dos principais atrativos, na ânsia de recuperar volume de mercado principalmente na alta temporada. Certamente, esse jogo de interesses se apóia mais nos aspectos econômicos do que ecológicos - o que foge dos preceitos de uma relação ecologicamente sustentável.

A riqueza de cavernas na Serra da Bodoquena coloca a região como uma das mais propícias ao desenvolvimento de atividades espeleoturísticas no país. Pesquisas recentes (CAMARGO e LOURENÇÃO, 2007) apontam para um total de mais de 150 cavidades naturais ente os municípios de Bonito, Jardim e Bodoquena. Destas, Lobo et al. (2008) apontam para um total de oito com algum tipo de uso público - algumas delas, temporariamente fechadas por questões de licenciamento ambiental. Na atualidade, apenas quatro cavernas estão abertas ao uso turístico na região: gruta do Lago Azul, gruta de São Miguel, abismo Anhumas e buraco das Araras.

A gruta do Lago Azul foi descoberta em meados dos anos quarenta do século passado, pelo antigo proprietário da área. Foi também um dos primeiros atrativos abertos oficialmente à visitação pública, em meados dos anos setenta. À mesma época, em 1978, foi tombada pelo Instituto do Patrimônio Histórico e Artístico Nacional - IPHAN -, o que foi justificado pelo seu excepcional valor cênico e sua importância científica (BOGGIANI et al., 2002; LINO et al., 1994; UFMS, 2002). Em 1982 a área que abriga a gruta do Lago Azul, em conjunto com a gruta Nossa Senhora Aparecida - que à época era também acessível de forma desordenada ao público - foi adquirida pelo Governo do Estado de Mato Grosso do Sul, em nome da Empresa de Turismo de Mato Grosso do Sul. Posteriormente, em 1998, foram registradas em definitivo no nome do Estado. Desde 1993 o acesso à gruta só é permitido quando acompanhado por guias de turismo. Em 2001, as grutas e sua área de entorno foram transformadas em uma 
Unidade de Conservação de Proteção Integral, por meio do Decreto $n^{\circ} 10.394$, de 11 de junho de 2001 (MATO GROSSO DO SUL, 2001).

O documento que rege a forma de uso público da gruta já foi elaborado, por meio de um Estudo de Impacto Ambiental - Relatório de Impacto Ambiental - EIA-RIMA. Este instrumento de manejo é pouco utilizado para cavernas em geral, dado que desde meados de 2001, recomenda-se a utilização de Planos de Manejo Espeleológico - PMEs - para este tipo de atrativo. Todavia, poucos elementos do EIA-RIMA da gruta foram implantados na prática, como o limite diário de visitação (305 pessoas por dia). Outros que seriam fundamentais para melhorar seu processo de gestão turística ainda não têm previsão de implantação, como o circuito interno de visitação em formato circular.

Mariani (2003) ressalta a necessidade de uma revitalização no entorno da gruta, comentando sobre a descaracterização gerada pela grade que controla o seu acesso. Para Marra (2001) a feitoria em questão é um fator positivo, por estar adequadamente afastada do pórtico da cavidade. Ambos os autores concordam sobre a necessidade de existência da grade para melhor controlar a visitação. Mas as pesquisas de campo permitiram concluir que a grade, além de artificializar a paisagem, é pouco eficaz nesse sentido, já que o controle de acesso do atrativo se dá em seu receptivo.

A gruta de São Miguel está localizada em uma propriedade particular. Sua visitação ocorre desde 1999, feita somente com guias e obedecendo aos limites de visitação impostos em seu PME: 285 pessoas/dia no verão e 255 no inverno, em grupos de até 12 pessoas. A redução se dá em função da diminuição da luz do dia no inverno, o que atrapalha a percepção do visitante na parte externa do roteiro.

A gruta foi toda estruturada para a visitação. Conta com ponte pênsil para o acesso externo, escadas internas de metal e madeira e iluminação artificial com lâmpadas fluorescentes compactas, trabalhadas em três níveis distintos. A iluminação de caminhamento serve para delimitar o roteiro de visitação. A de destaque é utilizada para dar ênfase aos aspectos cênicos do roteiro, como espeleotemas. Por fim, a de volume é utilizada para conferir perspectiva e profundidade de campo. Dentro da cavidade existem macas e kits de primeiros socorros para casos de emergências. Ao fim do passeio, um carrinho elétrico leva os turistas de volta ao receptivo. Em dias de chuva são fornecidos guarda-chuvas para a trilha externa, exclusividade deste atrativo. 
O abismo Anhumas foi descoberto acidentalmente em 1970 e visitado pela primeira vez em 1984. Sua porção submersa chega a $80 \mathrm{~m}$ de profundidade, que somados aos $72 \mathrm{~m}$ de rapel entre a entrada e o lago, totalizam 152 metros de desnível total. As visitas turísticas, que desde 1996 contavam com poucos aventureiros e mergulhadores, se intensificaram a partir de sua abertura oficial como produto turístico, em 1999. Conforme Costa Júnior (2004) o limite diário é de 18 visitantes, divididos em dois períodos, com no máximo 14 pessoas simultaneamente dentro da cavidade.

O sistema de segurança do Abismo Anhumas é um de seus pontos fortes. Um dia antes do passeio, todos os clientes precisam fazer um treinamento básico de técnicas verticais na sede do atrativo. Neste treinamento são verificadas as condições físicas e psicológicas dos clientes, que podem vir a ser reprovados. Neste caso, o valor do pagamento é integralmente devolvido. Além disso, os equipamentos do operacional de atividades verticais (rapel e jumar ${ }^{4}$ ) são trocados a cada seis meses ou quando necessário. Quanto à conservação legal de seu entorno, o abismo encontra-se em uma área de 56 hectares, que está passando por um processo de transformação em uma Reserva Particular do Patrimônio Natural - RPPN.

Sob o ponto de vista comercial, o Anhumas pode ser considerado como um fenômeno de marketing para roteiros espeleoturísticos no Brasil. O valor do ingresso para os passeios em seu interior está muito acima - entre vinte e cinqüenta vezes - dos valores praticados em outras cavernas brasileiras. No entanto, em determinadas épocas do ano é preciso fazer reservas com grande antecedência, dada a grande procura. Embora não tenham sido feitas pesquisas específicas sobre os porquês deste grande interesse do público, creditam-se preliminarmente os seus diferenciais à aventura, à exclusividade (status) e à qualidade dos serviços prestados.

O Buraco das Araras foi descoberto em 1912. Trata-se de uma das maiores dolinas do mundo, com 124 metros de profundidade e aproximadamente 500 metros de circunferência. Nos anos sessenta e setenta, era utilizado pelos moradores locais como cemitério de automóveis e de pessoas, provavelmente fruto de assassinatos por disputas de terras. Deus (2004) relata que em 1967 o exército fez uma primeira descida de rapel até o seu interior, para fins de treinamento militar. Em 1974, nova descida foi feita, desta vez, para retirada de ossadas humanas, roupas, objetos e carcaças de automóveis.

\footnotetext{
${ }^{4}$ Técnicas verticais com uso de cordas e equipamentos de segurança, respectivamente de descensão e ascensão.
} 
O turismo tem auxiliado na conservação ambiental do Buraco das Araras. Uma reportagem divulgada em 1996 na revista Os Caminhos da Terra relata a inexistência de araras no seu interior (RIBEIRO, 1996). Atualmente, quase oitenta casais de araras, além de tucanos e outros pássaros, nidificam e habitam em seu interior e entorno. O trabalho de conservação, aliado ao turismo e à educação ambiental desenvolvidos na trilha de aproximadamente 950 metros que circunda o Buraco colaboram para essa melhoria nas condições de vida da fauna. A área do Buraco e seu entorno, totalizando aproximadamente 25 hectares, foi recentemente transformada em uma RPPN. A visitação é feita acompanhada de guias, que desenvolvem um trabalho de interpretação e conscientização ambiental junto aos visitantes.

\section{A Importância Econômica do Espeleoturismo no Contexto Regional}

De um modo geral, existem atrativos espeleoturísticos para diferentes perfis socioeconômicos de consumo na Serra da Bodoquena. Os valores dos ingressos nos anos 2006/2007, variaram entre os R \$25,00 da gruta do Lago Azul e do buraco das Araras, os R \$32,00 da gruta de São Miguel e os R\$330,00 - rapel com flutuação - ou R\$480,00 - rapel com mergulho - do abismo Anhumas. Ao contrário de outros passeios da região, estes não praticam preços diferenciados na baixa temporada. A tabela 1 apresenta o total de visitantes destes atrativos entre os anos 2001 e 2005.

Tabela 1 - Fluxo espeleoturístico na Serra da Bodoquena

\begin{tabular}{|l|r|r|r|r|r|}
\hline \multirow{2}{*}{ CAVIDADE NATURAL } & \multicolumn{5}{|c|}{ TOTAL DE VISITANTES } \\
\cline { 2 - 6 } & \multicolumn{1}{c|}{2001} & \multicolumn{1}{c|}{2002} & \multicolumn{1}{c|}{2003} & \multicolumn{1}{c|}{2004} & \multicolumn{1}{c|}{2005} \\
\hline Gruta do Lago Azul & 46.056 & 51.078 & 48.364 & 44.014 & 45.116 \\
\hline Gruta de São Miguel & 6.432 & 8.847 & 11.894 & 8.950 & 5.756 \\
\hline Abismo Anhumas & 1.235 & 751 & 738 & 909 & 720 \\
\hline Buraco das Araras & -- & -- & 1.272 & 3.260 & 3.327 \\
\hline
\end{tabular}

Fonte de dados: Bonito (2005).

Os dados demonstram que a Serra da Bodoquena possui uma vocação para uma proposta de divulgação mais focada em seu potencial espeleoturístico. Considerando a média anual 
estimada de 70.000 turistas pela Associação de Atrativos Turísticos de Bonito e Região, a ATRATUR, percebe-se que em torno de 65\% destes visitam a Gruta do Lago Azul, mais da metade do total. Levando em conta os preços praticados em 2005, os atrativos espeleoturísticos geraram um montante bruto total de aproximadamente R 1.620 .000 (um milhão seiscentos e vinte mil reais). Isto considerando apenas os turistas que entraram no sistema via voucher ${ }^{5}$ unificado de Bonito. No caso do buraco das Araras, os turistas que chegam através do município Jardim não usam o sistema, podendo apresentar um fluxo ainda maior de visitantes do que o considerado. Não estão sendo computados os gastos indiretos destes turistas, com hospedagem, alimentação, entretenimento noturno, transportes, gastos nas lojas e outros. Tendo em vista o montante apontado e levando em conta que os valores pagos nos ingressos dos atrativos são divididos entre os proprietários de atrativos, agenciadores, guias de turismo, poder público e outros, percebe-se a sua importância no contexto econômico da Serra da Bodoquena. Por fim, cabe ressaltar que não foi possível obter uma dimensão da representatividade real desse segmento no contexto do turismo na região, visto que não existem dados precisos sobre o total de turistas que a visitam.

\section{Contribuições Técnicas para a Sustentabilidade Ecológica do Espeleoturismo na}

\section{Serra da Bodoquena}

O espeleoturismo busca nas técnicas de planejamento e manejo mecanismos que permitem a diluição das suas conseqüências negativas, por meio dos métodos de controle de visitação. Estes, baseados em procedimentos técnicos e científicos, visam à proposição de soluções como o zoneamento ambiental e a capacidade de suporte turístico-ambiental.

O zoneamento ambiental é uma técnica que deriva dos processos de planejamento de Unidades de Conservação. Trata-se do parcelamento espacial em função de determinadas classificações, que tomam por base a fragilidade e a potencialidade do meio, bem como seu grau de conservação (IBAMA, 2002). Esta mesma proposição vem sendo transportada para o manejo de cavernas, o que já seria passível de críticas, dado que os limites espaciais do meio subterrâneo são fatores limitantes para a classificação de zonas de uso. O EIA-RIMA da gruta

\footnotetext{
${ }^{5}$ O voucher unificado de Bonito é um instrumento de gestão implantado em 1995 pelo Conselho Municipal de turismo - COMTUR, com o objetivo inicial de controlar a arrecadação de impostos municipais dos prestadores de serviços turísticos. Todavia, o sistema já existia no município antes mesmo de sua formalização, sendo aplicado de formas diversas por algumas agências de receptivo e atrativos. A ação do COMTUR apenas normalizou e padronizou o trabalho. Em consequência, o voucher se transformou também em um instrumento de apoio à conservação ambiental, controlando os limites de visitação de cada um dos atrativos naturais locais (LUNAS, 2000).
} 
do Lago Azul foi feito com base nesta perspectiva crítica ora apresentada, privilegiando a delimitação do caminhamento por onde os turistas passam ao invés da criação de zonas de manejo que, muitas vezes, só existem no papel e possuem pouca ou nenhuma utilidade prática. A gruta de São Miguel e o abismo Anhumas - quer por opção, quer por obrigação utilizaram da técnica de zoneamento em seu planejamento. Entretanto, sob o ponto de vista da gestão do atrativo, o ponto fundamental é a delimitação do roteiro de visitação, o que também é feito nestes atrativos, bem como no buraco das Araras.

A capacidade de suporte turístico-ambiental diz respeito ao limite de uso que pode ser dado a um determinado ambiente sem que alterações irreversíveis em parâmetros importantes para o meio venham a ocorrer (CIFUENTES-ARIAS et al., 1999; LOBO, 2005; BOGGIANI et al., 2007). O consenso identificado entre os especialistas do tema é quanto à identificação destes parâmetros, o que pode levar a diversos equívocos de interpretação e à banalização da técnica com o objetivo de oferecer uma resposta quantitativa que, na maioria dos casos, é aplicada sem bom-senso por parte dos responsáveis pela gestão dos atrativos turísticos (DELGADO, 2006).

Dos métodos mais difundidos de identificação de capacidade de carga em cavernas, destacase por seu uso mais frequente no Brasil aquele desenvolvido por Miguel Cifuentes Arias e sua equipe para o manejo de trilhas em florestas tropicais da Costa Rica. A "Capacidade de Carga de Cifuentes" - nome pelo qual se popularizou - é uma metodologia de base quantitativa com raras possibilidades de adaptação para análises qualitativas.

Exemplos práticos do uso da capacidade de carga turística foram observados na Serra da Bodoquena, a começar pelo abismo Anhumas. Conforme Costa Júnior (2004), o limite de visitantes foi determinado em função do tempo que a atividade leva para ser executada - um rapel e jumar de 72 metros de altura, com possibilidade de flutuação ou mergulho no lago ao fundo da cavidade. Embora a dificuldade já estabeleça limites extremamente restritos para a visitação, não foram feitos estudos que demonstrem se estes limites praticados causam algum tipo de impacto mais severo ao meio.

O caso do abismo Anhumas decorre de uma série de fatores coincidentes que impedem o uso dos métodos conhecidos. A cavidade não apresenta alternativas de roteiro de visitação; os turistas entram e saem pelo mesmo lugar; e o acesso se dá por meio de cordas, uma forma mais técnica de visitação. A Capacidade de Carga de Cifuentes também não se aplica, dada à inexistência de uma trilha de acesso - base para o seu correto funcionamento. Que outra saída para mensurar o limite de visitação que não a capacidade operacional do atrativo? 
Uma das formas sugeridas por Swarbrooke (2000) como sendo a de menor eficiência na relação entre o controle de visitação e a conservação ambiental, exatamente por sua vulnerabilidade face às necessidades de mercado, culmina por ser o mais eficiente sistema de conservação ambiental para este caso específico. Tem-se nisso um interessante paradoxo entre a teoria e as práticas de manejo, o que demonstra a ineficiência da construção de modelos préconcebidos de planejamento e gestão.

A gruta de São Miguel também adota um sistema de controle de visitantes por meio da capacidade operacional, com total variável de visitas conforme a estação do ano: 285 pessoas no verão, 255 no inverno. Essa diferença - pequena considerando-se que o fluxo turístico no Brasil concentra-se no verão - existe em função da menor duração da luz do dia no inverno. Com pouca luz, a parte externa do roteiro perde parte de sua atratividade para a contemplação. Outra característica da gestão turística da gruta de São Miguel consiste no limite de apenas dez pessoas por grupo de visitantes, apesar de seu PME permitir até quinze. A redução no dimensionamento dos grupos é uma atitude que supostamente também contribui para a minimização dos impactos, além de ampliar o aproveitamento da atividade e a segurança do turista.

Por outro lado, o excesso de exigências no detalhamento dos estudos técnicos pode gerar situações inviáveis. As muitas limitações no número de visitantes tornam o produto turístico final inviável, ou demasiadamente seletivo. Tome-se como base para essa análise o caso do abismo Anhumas. O PME determina um máximo de 18 visitas diárias. Face aos custos gerados pela complexidade operacional do atrativo, o número representa uma drástica limitação na visitação, sobretudo quanto a que tipos de turistas podem visitar a cavidade. Percebe-se que os limites da técnica a favor da conservação do patrimônio espeleológico levam em conta também as necessidades do mercado. Principalmente quando aplicados em áreas particulares, onde existe o compromisso com a lucratividade do empreendimento.

Mas as técnicas têm sua utilidade para a conservação da natureza, quando utilizadas sob parâmetros isentos de compromissos mercadológicos. Propõe-se analisá-las sob os aspectos de suas limitações e também suas potencialidades. Nesse sentido, determinadas propostas podem ser validadas de forma a aproveitar os benefícios gerados pelas técnicas - quer em áreas públicas, quer em particulares. No caso das cavidades naturais da Serra da Bodoquena, uma série de pequenas contribuições pode ser considerada, como forma de auxiliar na construção de um espeleoturismo que consiga se aproximar de um ideário de uso responsável do patrimônio espeleológico. 
O primeiro grupo de contribuições versa sobre as possibilidades intrinsecamente limitadas de uso, em função das técnicas avançadas de exploração. É o caso de cavidades naturais cuja dificuldade de acesso impõe uma barreira à visitação. Desta forma, consegue manter a viabilidade econômica da execução da atividade e, simultaneamente, inibir a sua visitação massificada. Neste mesmo grupo, incluem-se as cavidades que requerem e/ou possibilitam a execução de técnicas verticais e de mergulho, como o abismo Anhumas.

O segundo grupo de contribuições dado pelas técnicas pode ser aplicado às cavidades cuja visitação é de caráter essencialmente contemplativo. Nesse caso, o acesso ao atrativo não carece de procedimentos avançados de exploração, o que possibilita um volume maior de visitas diárias. Sem a imposição de limites de visitação, a degradação ambiental pode ser quase irreversível.

A primeira recomendação é que se estabeleça, por meio de parâmetros científicos e não meramente operacionais, o número máximo de visitas diárias permitidas para cada um dos atrativos abertos à visitação. Isso poderia ser feito por meio da aplicação da metodologia de Capacidade de Carga (CIFUENTES-ARIAS et al., 1999), em casos como o da gruta de São Miguel e do buraco das Araras.

Sobre a gruta do Lago Azul, questiona-se em primeira instância a estrutura interna de acesso e segurança do atrativo. Ressalta-se que a política de gestão para a gruta tem se empenhado em executar atividades corretivas ao invés de preventivas. Tome-se como exemplo o caso do uso de capacete para a visitação. A sua obrigatoriedade surgiu apenas depois de um incidente, ocorrido em dezembro de 2004, com a queda de um bloco de estalactites próximo a um grupo de turistas. Sendo uma cavidade natural como qualquer outra, por que se demorou tanto para a aplicação de uma regra básica de segurança? Esse tipo de negligência ainda ocorre na visitação do atrativo, e seu maior expoente é a falta de um corrimão junto às escadas de acesso. A ausência é justificada no próprio EIA-RIMA, alegando o comprometimento visual e estético da paisagem subterrânea.

Ao que se pôde observar em campo, a gruta do Lago Azul é a cavidade natural que conta com o sistema de segurança mais frágil na visitação. A falta de corrimão para o acesso é um exemplo deste problema, afetando a segurança do visitante pela existência de diversas áreas de penumbra na trilha interna, em função da posição de alguns blocos rochosos. Muito embora o corrimão possa vir a ser um impacto estético, trata-se de uma estrutura fundamental para a segurança do visitante. Assim como a implantação de pontos de luz em determinados trechos da trilha interna, para diminuir as sensações de desconforto e insegurança nos turistas. 
Isto se apóia em princípios de interpretação ambiental, que levantam a necessidade de que o turista se sinta tranqüilo e seguro para vivenciar melhor a experiência de visitação.

Além disso, o perfil do turista que visita a Serra da Bodoquena tem se modificado cada vez mais, com o aumento da quantidade de famílias e turistas da melhor idade, em detrimento de jovens aventureiros. Como já foi destacado por Vargas (2000, p. 143), esse novo tipo de turistas "precisa de uma estrutura especial que proporcione atrativos adequados".

Outro aspecto importante do turismo na gruta do Lago Azul é o seu cálculo de Capacidade de Carga, que direciona os limites de visitação. O EIA-RIMA determina um número máximo de 264 e 95 visitantes diários, respectivamente em dias não chuvosos e chuvosos, para um percurso linear de 162,5 metros (UFMS, 2002). Atualmente, a gruta trabalha com 305 visitas diárias, o que está dentro do valor máximo de 330 visitantes por dia em função das condições ideais de manejo.

Mas existem pontos determinados pela metodologia de Cifuentes que o EIA-RIMA não leva em conta. Conforme Cifuentes-Arias et al. (1999), um dos pressupostos iniciais para o funcionamento correto da metodologia é que a visitação se dê em um único sentido da trilha, ou seja, sem retorno pelo mesmo caminho. No caso da gruta do Lago Azul, em função da trilha interna ainda não ter sido totalmente implantada, o percurso de visitação atual é feito com a ida e a volta pelo mesmo caminho. Ao se considerar que os limites atuais de 305 visitas por dia são para caminhamento em um único sentido, pode-se concluir que com os turistas indo e voltando pelo mesmo percurso, existe a possibilidade de se ampliar alguns dos impactos considerados para a visitação.

Seria o caso de afirmar que o número ideal neste caso é a metade do valor praticado? Uma lógica matemática simples apontaria para este resultado, ao se dividir o valor total de visitas diárias pelo número de vezes que cada visitante passa no mesmo lugar, ou seja, duas. Mas o determinismo metodológico precisa ser olhado com ponderação, pois não se sabe ao certo se os impactos realmente se duplicam. Um exemplo já pesquisado é a dinâmica microclimática da cavidade natural. Boggiani et al. (2007) demonstram que a amplitude térmica e hígrica na gruta do Lago Azul recebe grande influência do meio externo, diferentes do padrão da maioria das cavidades naturais (cf. HEATON, 1986; STOEVA e STOEV, 2005). Assim se abrem opções para que se verifique inclusive a possibilidade de ampliação no total de visitas diárias, seja pela constatação da inexistência de impactos significativos, seja pela ampliação do circuito de visitação, tal como preconizado em seu EIA-RIMA. 
Outro aspecto observado é que o cálculo de capacidade de carga levou em conta apenas aspectos antropogênicos, como a acessibilidade e o piso escorregadio. Isto a torna deficiente, já que o objetivo principal da aplicação de um método de manejo como este é a identificação das fragilidades ambientais na redução do número de visitas diárias permitidas, face à sua susceptibilidade de dano por ação e/ou presença humanas.

Decorrente de qualquer prática de alteração no número total de visitantes permitidos na gruta do Lago Azul, vislumbram-se conseqüências para a sua gestão. A primeira delas seria sobre o ganho qualitativo na visitação no caso de diminuição no total de visitas diárias, pois com um número menor de turistas, os freqüentes, desagradáveis e perigosos encontros na trilha interna entre os grupos de turistas seriam minimizados ou até mesmo eliminados. Por outro lado, a limitação pode gerar o paradoxo que obriga o preço a subir, em uma perspectiva mercadológica de gestão, que visa à manutenção e o aumento da lucratividade - prática pouco recomendável em casos como o da gruta do Lago Azul, um patrimônio da humanidade que deve ser acessível à maioria das pessoas e não somente por meio de uma parcela da sociedade financeiramente selecionada (LOBO et al., 2007).

\section{Conclusões}

O espeleoturismo já se desenvolve na Serra da Bodoquena, mas sem o reconhecimento do próprio destino quanto às suas especificidades e diferenciações mercadológicas. Este aspecto não é de se estranhar, dado que o ideário de espeleoturismo enquanto segmento de mercado ainda é recente, se tratando de uma atividade emergente na gama de possibilidades do turismo de natureza (SCALEANTE, 2005; LOBO et al., 2008). Ainda não se aproveitam as nuanças e o imaginário existente em cada uma das formas, técnicas e tipos de exploração espeleoturística e outras práticas desenvolvidas. A identidade centralizadora de todas as possibilidades turísticas já existentes se consolida no turismo de natureza, executado sob o pano de fundo de um turismo dito sustentável. Entretanto, a breve análise realizada sobre alguns poucos aspectos ecológicos permite afirmar que o turismo desenvolvido na região não é amplamente sustentável.

O espeleoturismo pode vir a representar na Serra da Bodoquena a materialização de uma concepção mais responsável de relação entre o turismo e a natureza. Para tanto, precisa ser produzido de forma a considerar o controle de visitação e as múltiplas facetas do patrimônio espeleológico. Por possuir limitações e possibilidades definidas, o espeleoturismo se mostra 
viável como uma prática coerente com os preceitos do ecoturismo, o que é essencial para a sobrevivência do turismo que tem a frágil paisagem cárstica como atrativo principal.

Outro aspecto observado é a necessidade de aprimoramento nos métodos, técnicas e sistemas de manejo e gestão de cavidades naturais para fins turísticos no Brasil. A mera aplicação de sistemas adaptados de unidades de conservação e do manejo de trilhas pode perpetuar equívocos que mesmo em suas áreas de origem já vêm sendo superados em diversas partes do mundo. No caso específico do espeleoturismo, diversos estudos (e.g. CIGNA e FORTI, 1988; HOYOS et al., 1998; CALAFORRA et al. 2003; BOGGIANI et al., 2007) têm demonstrado a possibilidade de aplicação de técnicas científicas de pesquisa para o melhoramento dos princípios e bases de manejo. As cavidades naturais da Serra da Bodoquena estão entre aquelas onde existe um sistema mais aprimorado de controle em relação aos demais atrativos espeleoturísticos do Brasil. Todavia, é um exemplo positivo-relativo, dado que o que se exalta não é a alta qualidade das práticas adotadas na região, mas sim, a situação problemática do panorama nacional do setor.

Por fim, conclui-se que o espeleoturismo na Serra da Bodoquena pode ser melhorado em suas questões ecológicas e conservacionistas, de forma a se tornar um exemplo para o turismo local. Desta forma, descortinam-se possibilidades para que este atue na conscientização, educação e conservação ambiental, rompendo com as formas mais convencionais do turismo de natureza e ampliando sua sustentabilidade ecológica.

\section{Referências}

BARBOSA, M.A.C.; ZAMBONI, R.A. 2000. Formação de um cluster em torno do turismo de natureza sustentável em Bonito - MS. Brasília: MPOG/IPEA.

BOGGIANI, P.C. 2001. Ciência, meio ambiente e turismo em Bonito: a combinação que deu certo? In: BANDUCCI JÚNIOR, A.; MORETTI, E.C. (orgs.). Qual paraíso? Turismo e ambiente em Bonito e no Pantanal. São Paulo: Chronos/UFMS.

BOGGIANI, P.C.; COIMBRA, A.M.; DESICKI, A.L.D.; SIAL, A.N.; FERREIRA. V.P.; RIBEIRO, F.B.; FLEXOR, J.M. 2002. Tufas calcárias da Serra da Bodoquena, MS: cachoeiras petrificadas ao logo dos rios. In: WINGE, M. et al. (eds.) Sítios geológicos e paleontológicos do Brasil. Brasília: DNPM/CPRM.

BOGGIANI, P.C.; SILVA, O.J. da; GESICKI, A.L.D.; GALLATI, E.A.B.; SALLES, L. de O.; LIMA, M.M.E.R. 2007. Definição de capacidade de carga turística das cavernas do Monumento Natural Gruta do Lago Azul (Bonito,MS). Geociências, Rio Claro, v. 26, n. 4, p. 333-348.

BONITO (Município). 2005.Total de visitantes por passeio. Bonito: Central do ISSQN.

BRASIL. MMA. MICT. IBAMA. EMBRATUR. 1994. Diretrizes para uma política nacional de ecoturismo. Brasília: EMBRATUR. 
CALAFORRA，J.M.; FERNÁNDEZ-CORTÉS，A.; SÁNCHEZ-MARTOS，F.; GISBERT， J.; PULIDO-BOSCH, A. 2003. Environmental control for determining human impact and permanent visitor capacity in a potential show cave before tourist use. Environmental Conservation, v. 30, n. 2, p. 160-167.

CAMARGO, R.R.; LOURENÇÃO, M.L.F. 2007. Levantamento espeleológico da Serra da Bodoquena. In: Congresso Brasileiro De Espeleologia, 29, Ouro Preto. Anais do Congresso Brasileiro de Espeleologia: Ouro Preto, MG: SEE/SBE, p. 1-7.

CIFUENTES-ARIAS, M.C.; MESQUITA, C.A.B.; MÉNDEZ, J.; MORALES, M.E.; AGUILAR, N.; CANCINO, D.; GALLO, M.; RAMIREZ, C.; RIBEIRO, N.; SANDOVAL, E.; TURCIOS, M. 1999. Capacidad de carga turística de las áreas de uso público del Monumento Nacional Guayabo, Costa Rica. Turrialba: CATIE/WWF.

CIGNA, A.A.; FORTI, P. 1988. The environmental impact assessment of a tourist cave. In: Cave Tourism International Symposium at-170 Anniversary of Postojnska Jama, Postojna (Yugoslavia), 1988, Postojna. Proceedings. Postojna: UIS, p. 29-38.

COSTA JÚNIOR, E.P.D. 2004. Abismo Anhumas (MS 04): Plano de Manejo Espeleológico. rev. e ampl. Bonito: Abismo Anhumas.

DELGADO, M. 2007. Análise da metodologia criada por Miguel Cifuentes referente à capacidade de carga turística. Turismo em Análise, São Paulo, v. 18, n. 1, p. 73-93, maio.

DEUS, R.S. 2004. Reestruturação da trilha de visitação no entorno do Buraco das Araras - JardimMS. Jardim, UEMS, 2004. Trabalho de Conclusão de Curso (Graduação em Turismo), Universidade Estadual de Mato Grosso do Sul.

GNASPINI, P.; TRAJANO, E.; SÁNCHEZ, L.E. 1994. Província espeleológica da Serra da Bodoquena, MS: exploração, topografia e biologia. Espeleotema, Monte Sião, v. 17, p. 19-42.

HEATON, T. 1986. Caves: A tremendous range in energy environments on earth. National Speleological Society News, Huntsville, v. 08, n. 44, p. 301-4.

HOYOS, M.; SOLER, V.; CAÑAVERAS, J.C.; SÁNCHEZ-MORAL, S.; SANZ-RUBIO, E. 1998. Microclimatic characterization of a karstic cave: Human impact on microenvironmental parameters of a prehistoric rock art cave (Candamo Cave, Northern Spain). Environmental Geology, v. 33, n. 4, p. 231-242.

IBAMA. 2002. Roteiro metodológico de planejamento: Parque Nacional, Reserva Biológica, Estação Exológica. Brasília: MMA/IBAMA.

LABEGALINI, J.A. 1996. Levantamento dos impactos das atividades antrópicas em regiões cársticas - Estudo de caso: Proposta de mínimo impacto para implantação de infra-estrutura turística na Gruta Lago Azul - Serra da Bodoquena (Município de Bonito, MS). São Carlos: USP, 1996. Dissertação (Mestrado em Ciências da Engenharia Ambiental), Universidade de São Paulo.

LINO, C.F.; BOGGIANI, P.C.; CORTESÃO, J.; GODOY, N.M.; KARMANN, I. 1984. Projeto grutas de Bonito (MS): diretrizes para um plano de manejo turístico. São Paulo: MSTUR/SPHAN/FNPM.

LOBO, H.A.S. 2005. Considerações Preliminares Para a Reestruturação Turística da Caverna de Santana - PETAR, Iporanga, SP. In: Congresso Brasileiro de Espeleologia, 28, Campinas. Anais. Campinas: SBE, p. 77-87.

LOBO, H.A.S. 2006. O lado escuro do paraíso: espeleoturismo na Serra da Bodoquena. Aquidauana: UFMS, 2006. Dissertação (Mestrado em Geografia), Departamento de Geociências, Universidade Federal de Mato Grosso do Sul.

LOBO, H.A.S.; PEREIRA, C.H.; ALMEIDA, J.B. de. 2007. Patrimônio para quem? Os turistas que visitam a gruta do Lago Azul - Bonito, MS. In: Encontro Nacional de Turismo com Base Local, 10, João Pessoa. Anais - Tomo I. João Pessoa: UFPB/ENTBL, p. 1361-1369. 
LOBO, H.A.S.; PERINOTTO, J.A. de J.; BOGGIANI, P.C. 2008. Espeleoturismo no Brasil: Panorama Geral e Perspectivas de Sustentabilidade. Revista Brasileira de Ecoturismo, São Paulo, v. 1, n. 1, p. $62-83$.

LUNAS, J.R. da S. 2000. Turismo sustentável: Descrição e Avaliação da Gestão do Turismo de Bonito-MS. Brasília: Editora da UnB. Dissertação (Mestrado em Desenvolvimento Sustentável), Centro de Desenvolvimento Sustentável, Universidade de Brasília.

MARIANI, M.A.P. 2003. Turismo e meio ambiente no paraíso das águas. Campo Grande: UCDB.

MARRA, R.J.C. 2001. Espeleo turismo: planejamento e manejo de cavernas. Brasília: WD Ambiental.

MATO GROSSO DO SUL. 2001. Decreto $n^{\circ} 10.394$ de 11 de junho de 2001. Institui o Monumento Natural Gruta do Lago Azul. Campo Grande: Mato Grosso do Sul.

Pantanal. 2001. São Paulo: Chronos/UFMS.

PIRES, P.S. 2002. Dimensões do ecoturismo. São Paulo: SENAC.

RIBEIRO, R. 1996. Bonito demais. Os caminhos da Terra, São Paulo, n. 5, ed. 49, p. 10-21, maio.

SCALEANTE, J.A.B. 2005. Uso de cavernas como produto turístico. In: TRIGO, L.G.G.; PANOSSO NETTO, A.; CARVALHO, M.A.; PIRES, P. dos S. (eds.) Análises regionais e globais do turismo brasileiro. São Paulo: Roca.

SILVA. L.F.; CAMARGO, R.R. 2008. Valoração econômica das cavernas da microbacia do rio Salobra, Bodoquena-MS como subsídio ao planejamento ecoturístico. Pesquisas em Turismo e Paisagens Cársticas, v. 1, n. 1, p. 121-130. dez.

STOEVA, P.; STOEV, A. 2005. Cave air temperature response to climate and solar and geomagnetic activity. Memorie Della Societá Astronomica Italiana, v. 76, p. 1042-1047.

SWARBROOKE, J. 2000. Turismo sustentável: gestão e marketing. 2.ed. Tradução Esther Eva Horovitz. São Paulo: Aleph.

. 2002. Turismo sustentável: conceitos e impacto ambiental. 3.ed. Tradução Esther Eva Horovitz. São Paulo: Aleph.

UFMS. 2002. Estudo de impacto ambiental da visitação turística do Monumento Natural Gruta do Lago Azul - Bonito, MS. Campo Grande: UFMS.

VARGAS, I.A. 2001. A gênese do turismo em Bonito. In: BANDUCCI JÚNIOR, Á.; MORETTI, E.C. (orgs.). Qual paraíso? Turismo e ambiente em Bonito e no Pantanal. São Paulo: Chronos/UFMS.

\section{Recebido em: 27/09/2007 (1 ${ }^{\text {a }}$ versão) $28 / 11 / 2008$ ( $2^{\text {a }}$ versão) $23 / 03 / 2009$ (3 ${ }^{\text {a }}$ versão) Aprovado em: 18/05/2009}

